\title{
ARCHIPELAGO: A Dedicated Resource for Exploiting Past, Present, and Future Genomic Data on Disease Resistance Regulation in Rice
}

\author{
E. Vergne, ${ }^{1}$ E. Ballini, ${ }^{1}$ G. Droc, ${ }^{2}$ D. Tharreau, ${ }^{1}$ J.-L. Nottéghem,${ }^{1}$ and J.-B. Morel ${ }^{1}$ \\ ${ }^{1}$ UMR BGPI INRA/CIRAD/Montpellier SupAgro, Campus International de Baillarguet, TA A54/K, 34398 Montpellier, France; \\ ${ }^{2}$ UMR DAP CIRAD TA A96/03 Avenue Agropolis 34398 Montpellier Cedex 5, France
}

Submitted 7 January 2008. Accepted 12 March 2008.

\begin{abstract}
Large amounts of expression data dealing with biotic stresses in rice have been produced in the past 5 years. Here, we extensively review approximately 70 publications and gather together information on more than 2,500 genes of the rice defense arsenal. This information was integrated into the OryGenesDB database. Several genes (e.g., metallothioneins and PBZ1) appear to be hallmarks of ricepathogen interactions. Cross-referencing this information with the rice kinome highlighted some defense genes and kinases as possible central nodes of regulation. Cross referencing defense gene expression and quantitative trait loci (QTL) information identified some candidate genes for QTL. Overall, pathogenesis-related genes and disease regulators were found to be statistically associated with disease QTL. At the genomic level, we observed that some regions are richer than others and that some chromosomes (e.g., 11 and 12), which contain a lot of resistance gene analogs, have a low content of defense genes. Finally, we show that classical defense genes and defense-related genes such as resistance genes are preferentially organized in clusters. These clusters are not always coregulated and individual paralogs can show specific expression patterns. Thus, the rice defense arsenal has an ARCHIPELAGO-like genome structure at the macro and micro level. This resource opens new possibilities for marker-assisted selection and QTL cloning.
\end{abstract}

Plants are constantly exposed to microbial attacks and have developed sophisticated systems to counteract them. Besides the preformed defense systems such as cuticle (Skamnioti and Gurr 2007) and cell wall strengthening (Juge 2006), active resistance that requires both transcriptional (Dangl and Jones 2001) and post-transcriptional changes (Walling 2006) is usually mounted. This pathway can be divided into three steps. In the first step, the presence of the pathogen is detected by the plant throughout different recognition systems involving resistance $(R)$ genes or other pattern recognition receptors (Bent and Mackey 2007; Jones and Dangl 2006). Whereas some $R$ genes directly recognize pathogen molecules, other $R$ genes indirectly

Corresponding author: J.-B. Morel; Telephone: +33 499624 837; Fax: +33 499624 822; E-mail: jbmorel@ cirad.fr

*The $e$-Xtra logo stands for "electronic extra" and indicates that five supplemental tables and five supplemental figures are published online. recognize metabolic perturbations triggered by the pathogen (guard hypothesis) (Jones and Dangl 2006). Depending of the presence or absence of $R$ genes, the interaction will be incompatible (plant is resistant) or compatible (plant is susceptible). These $R$ genes are usually expressed constitutively, although some regulation exists (Vergne et al. 2007). In a second step, signal transduction occurs and requires regulators such as mitogen-activated protein kinases (Mishra et al. 2006) and transcription factors (Eulgem 2005). Here, the genes that are not $R$ genes are collectively called intracellular disease regulator $(I D R)$ genes. Although usually first defined genetically by mutants affected in disease resistance, IDR genes are also often differentially expressed (Vergne et al. 2007). In a third step, defense responses are induced. These include production of antimicrobial secondary metabolites (phytoalexins) (Peters 2006), pathogenesis-related (PR) proteins (e.g., chitinases and glucanases) (Jwa et al. 2006), cell-wall strengthening (Hückelhoven 2007), and programmed cell death, leading to the hypersensitive response (HR) (Greenberg and Yao 2004). These genes that act downstream of the disease resistance signaling pathway are collectively called defense genes.

For the purpose of this review, the disease resistance pathway is thus divided into three steps, where $R$ genes detect the pathogen and $I D R$ genes transduce the signal generated by $R$ genes to finally activate defense responses. In addition to these structural definitions, differential expression upon infection can be use to classify the genes. Here, we will use the term defenserelated genes for genes that are differentially expressed upon infection. As mentioned above, there are examples of $R, I D R$, and defense genes (including $P R$ genes) that belong to the class of defense-related genes.

Genetic and molecular analyses in Arabidopsis thaliana have demonstrated that most elements involved in these three steps (recognition, signal transduction, and induction of defense) are common to different types of pathogens and plants (Dangl and Jones 2001). At the genomic level, $R$ genes are known to be organized in clusters (Ballini et al. 2008; Monosi et al. 2004). No information on the genomic organization of IDR and defense-related genes is currently available.

Some efforts have been made in the past to centralize available information on defense responses. For example, the DRASTIC database (Button et al. 2006) referenced a large amount of data on several plant-pathogen interactions. With the genomic era, transcriptomic and proteomic approaches have generated large sets of data that are often dispersed and require dedicated tools for their integration. For example, in 
Arabidopsis this has been completed for most of the available Affymetrix transcriptomic data (Zimmermann et al. 2004). This was made possible by the fact that a limited number of types of techniques and DNA chips were used.

In the past decade, rice has emerged as a central plant model for monocots (Shimamoto and Kyozuka 2002). Rice has important advantages compared with other monocots, including reverse genetic databases (An et al. 2005; Droc et al. 2006; Miyao et al. 2007; Wu et al. 2005; Zhang et al. 2006) now containing more than 160,000 insertion lines, easy transformation protocols (Sallaud et al. 2004; Toki et al. 2006), and fullgenome sequences of indica and japonica cultivars (Goff et al. 2002; Yu et al. 2002). In addition, the genomes of three major rice pathogens-Magnaporthe oryzae (Dean et al. 2005), Xanthomonas oryzae pv. oryzae (Lee et al. 2005), and Rice yellow mottle virus (RYMV) (Yassi et al. 1994) — have been fully sequenced and are genetically accessible. These naturally occurring pathogens cause important field losses (e.g., blast disease caused by $M$. oryzae is a major cause of crop loss worldwide) (Valent 2004). Rice feeds more than half of the world's population (Khush 2005) and extensive quantitative trait loci (QTL) studies have been conducted to identify genetic determinants of disease resistance and improve rice tolerance through marker-assisted breeding. Some of these QTL to various rice diseases were recently anchored in the rice genome (Wisser et al. 2005). This led to the identification of chromosomal segments associated with broad-spectrum quantitative disease resistance. An extensive analysis of blast disease QTL is presented in an accompanying article (Ballini et al. 2008).

Wisser and associates (2005) noted that some gene families associated with QTL were found in clusters of several paralogs; however, this observation was not further studied and only limited examples of gene expression in such clusters are available in rice (Chittoor et al. 1997). Recently, it was demonstrated that genes automatically annotated as involved in biotic stress are found in clusters in A. thaliana and rice (Rizzon et al. 2006). This is a common observation for $R$ genes (Monosi et al. 2004). However, no global comparison between expression data and genomic structure of the defense arsenal in rice has been made.

Wisser and colleagues also observed that some gene families, such as glutathione- $S$ transferases and some proteases, were significantly associated with disease QTL (Wisser et al. 2005). Two major models for quantitative resistance are usually proposed. In the first model, quantitative resistance is the result of defective $R$ genes that recognize pathogens with low efficiency. This is supported by the observation that QTL, $R$ genes, and resistance gene analogs (RGA) seem to colocalize (Wisser et al. 2005), although this conclusion may suffer from technical drawbacks (Ballini et al. 2008), including a significant probability of colocalization only by chance. An example of such a case is provided by the RFO1 gene in Arabidopsis.
This gene confers quantitative resistance to Fusarium oxysporum (Diener and Ausubel 2005). A second model, which may not be mutually exclusive, suggests that defense-related genes (including defense genes such as $P R$ genes), as the final executers of resistance, explain significant parts of quantitative resistance. This is supported by the work of Ramalingam and associates (2003) and Liu and associates (2004), which shows that marker-assisted selection using defense-related genes improves blast resistance in rice. However, there is no global demonstration of statistically significant colocalization of defense-related genes and QTL (Ballini et al. 2008). An alternative model that has not yet been thoroughly explored is the possibility that IDR genes could explain some QTL. Rice is a good system to examine this possibility because this approach requires extensive QTL knowledge and IDR identification. Thus, a prerequisite for such a study is a complete inventory of both QTL and IDR genes.

In the past 5 years, there has been an exponential increase in the amount of available information on rice genes and proteins that are differentially expressed upon infection by pathogens and pathogen-related stresses. As the volume of this type of data continues to grow, there is a clear need for an integrated resource that would allow new datasets to be compared with previous results. Thus, we conducted an extensive review of such studies and integrated the resulting resource, called ARCHIPELAGO, into the web-based database OryGenesDB.

\section{Building the ARCHIPELAGO resource.}

All types of rice-pathogen interaction were considered, including experiments where elicitors and signaling molecules such as jasmonic acid were used to induce defense (see Supplementary Table 1 for the complete list of publications included). Some data originated from experiments where expressed sequence tag libraries were used to perform in silico expression; this represents 1,415 genes of the "Expressed" category (Table 1). The majority of the genes originated from experiments where differential information was directly available (e.g., microarray, differential-display, and protein twodimensional electrophoresis data) and were grouped in the category "Differentially expressed" (Table 1). This category represents more than 2,500 genes that are hereafter referred to as defense-related genes. Finally, genes from the kinome database (Dardick et al. 2007), which were identified by yeasttwo-hybrid and tandem affinity purification tag (TAP-TAG) experiments, were included because they represent proteins that interact with putative $R$ genes and signal transduction regulators. Disease regulators (IDR genes) such as NPRl were also included because some have been proven to be differentially expressed upon infection (Vergne et al. 2007). Overall, this represents a total of approximately 4,500 genes (approximately $10 \%$ of the gene pool) from approximately 70 publications. More than $65 \%$ of the "differentially expressed" cate-

Table 1. Gene content and origin of the ARCHIPELAGO resource

\begin{tabular}{llrr}
\hline Category & \multicolumn{1}{c}{ Additional information } & Publications & Gene number \\
\hline Expressed upon infection & Bacteria, elicitor, Magnaporthe grisea & 6 & 1,415 \\
Differentially expressed & Magnaporthe oryzae infection & 31 & 4 \\
& Bacteria infection & 17 & 273 \\
& Elicitor treatment & 2 & 323 \\
& Insect (BPH) attack & 3 & 115 \\
& Lesion mimic mutant & 1 & 117 \\
Disease regulators & Virus (Rice yellow mottle virus) infection & 1 & 22 \\
& $\ldots$ & 59 & 35 \\
Kinome data & Total for differentially expressed gene & 1 & 2,562 \\
& Yeast two-hybrid data & 1 & 127 \\
& Tandem affinity purification tag (TAP-TAG) data & 384 \\
& Total & 67 & 4,488 \\
\hline
\end{tabular}


gory was obtained from $M$. oryzae, suggesting that other types of plant-pathogen interactions are probably under-represented.

This wealth of data was integrated into the OryGenesDB database (Droc et al. 2006) together with new data on blast QTL, metaQTL, $R$ genes, and RGA (Ballini et al. 2008). Classical search and display tools associated with OryGenesDB are available (Fig. 1; Supplementary Fig. 3) (e.g., pop-up windows that display, for a given feature, the functional category, such as differentially expressed, and additional links, including PubMed links). Anchoring this information on the rice physical genome map allowed several different series of analyses.

\section{Identification of ubiquitous markers of defense.}

For defense-related genes identified in interactions with $M$. oryzae, there were sufficient data to establish comparisons of global biological function (Supplementary Fig. 1). Two functional categories are over-represented when compared with a random pool of genes. These include genes annotated as involved in cell death (MYB transcription factors and MLO proteins) and transcription factors. This confirms previous hypotheses that intense reprogramming occurs during disease resistance (Dangl and Jones 2001). In contrast, $R$ gene analogs did not seem to be massively differentially regulated upon infection. For example, only $5.5 \%$ of the 959 RGA listed in ARCHIPELAGO (Ballini et al. 2008) were differentially expressed in interactions between rice and $M$. oryzae. In contrast, we observed that $63 \%(22 / 35)$ of the $I D R$ genes (Table 1 , disease regulators) were differentially expressed upon $M$. oryzae infection (Supplementary Table 3).

Any potential overlaps between different types of interactions with $M$. oryzae, $X$. oryzae, RYMV, and insects were evaluated (Supplementary Fig. 2). Approximately $30 \%$ of the genes induced by bacteria, virus, and insects were also induced by $M$. oryzae. There were no genes found in common between

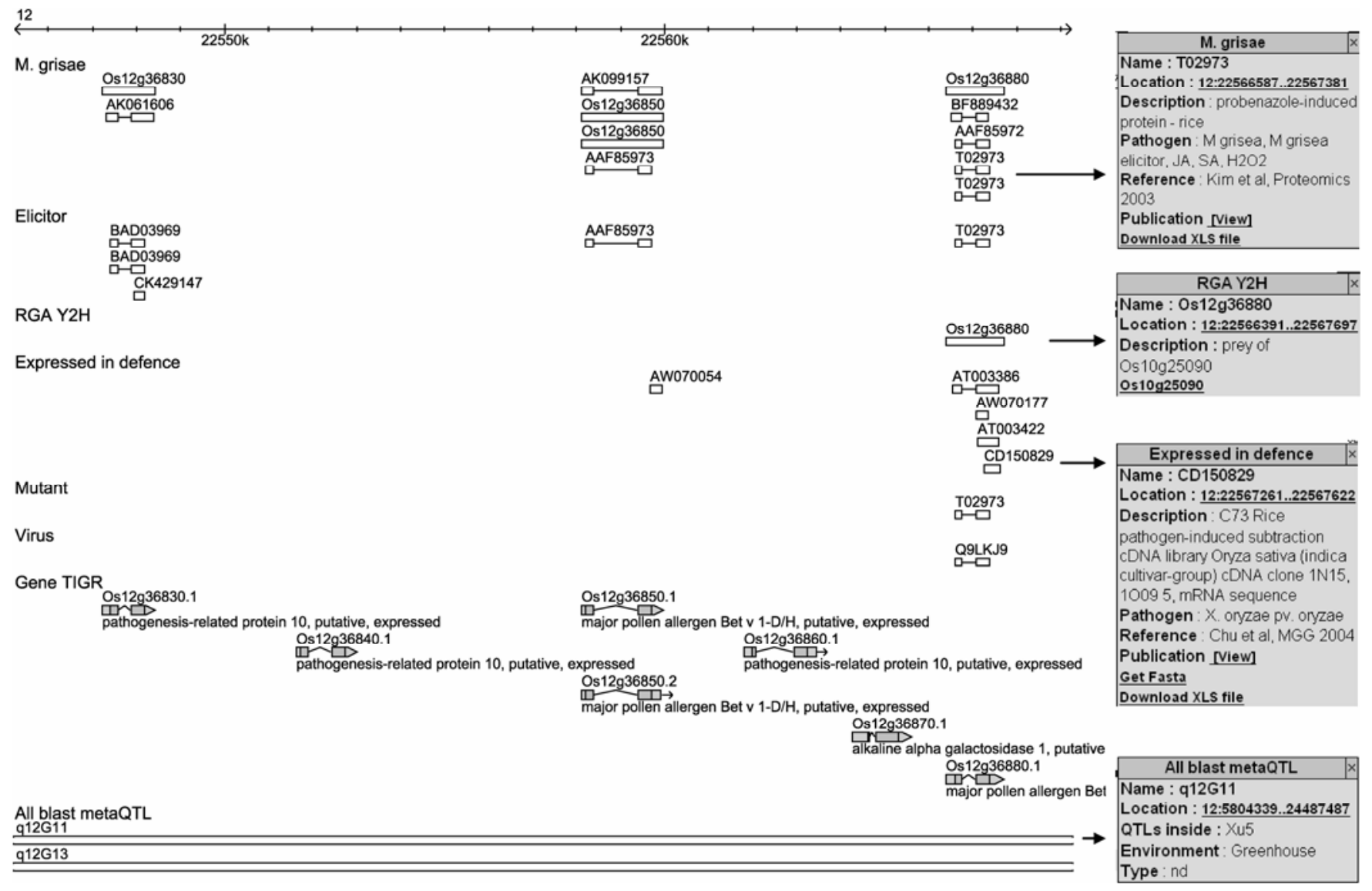

Fig. 1. The ARCHIPELAGO resource display in OrygenesDB illustrated by the $P B Z 1$ cluster on chromosome 12. Only eight annotation layers are shown but more are available on OrygenesDB. The panels on the right provide examples of the pop-up windows attached to each feature. Links to more detailed files or positions on the genome are underlined.

Table 2. Genes found differentially expressed in interactions with Magnaporthe oryzae and at least two other interactions

\begin{tabular}{llccccc}
\hline Tigr name & \multicolumn{1}{c}{ Putative function } & Bacteria & Elicitor & $\begin{array}{c}\text { Insect } \\
(\text { BPH })\end{array}$ & $\begin{array}{c}\text { M. oryzae } \\
\text { Mutant }\end{array}$ & $\begin{array}{c}\text { MYrus } \\
(\mathbf{R Y M})^{\mathbf{a}}\end{array}$ \\
\hline Os01g10400 & Expressed protein & 1 & 1 & 1 & 1 & 1 \\
Os01g21250 & Protein induced upon tuberization & 1 & 0 & 1 & 1 & 0 \\
Os02g52390 & Protein hypA & 1 & 0 & 1 & 1 & 0 \\
Os05g11320 & Metallothionein-like protein type 3 & 1 & 1 & 1 & 1 & 0 \\
Os10g32550 & Chaperonin CPN60-1, mitochondrial precursor & 0 & 1 & 0 & 1 & 1 \\
Os11g26850 & Adenosylhomocysteinase & 1 & 1 & 0 & 1 & 1 \\
Os12g17600 & Ribulose bisphosphate carboxylase small chain C & 1 & 0 & 1 & 1 & 1 \\
Os12g36880 & Major pollen allergen Bet v 1-D/H & 0 & 1 & 0 & 1 & 1 \\
\hline
\end{tabular}

${ }^{\mathrm{a}} \mathrm{RYMV}=$ Rice yellow mottle virus. 
insects and RYMV; however, this may be due to under-representation of these biological conditions in our database. The limited overlaps ( 81 genes) found between $M$. oryzae and bacterial infection are consistent with previous observations. For example, using macroarrays, Li and associates (2006) showed that approximately $15 \%$ of the genes differentially expressed were common to both pathogens. Seven genes were often found associated with response to different infection situations (Table 2). Two classes of genes could be distinguished. The first represents genes involved in cellular stress (e.g., metallothionein and PBZ1). The Os01g10400 gene was one of two metallothioneins found in almost all situations of biotic stress

Table 3. Rice genes differentially expressed upon Magnaporthe oryzae infection and interacting with the rice kinome

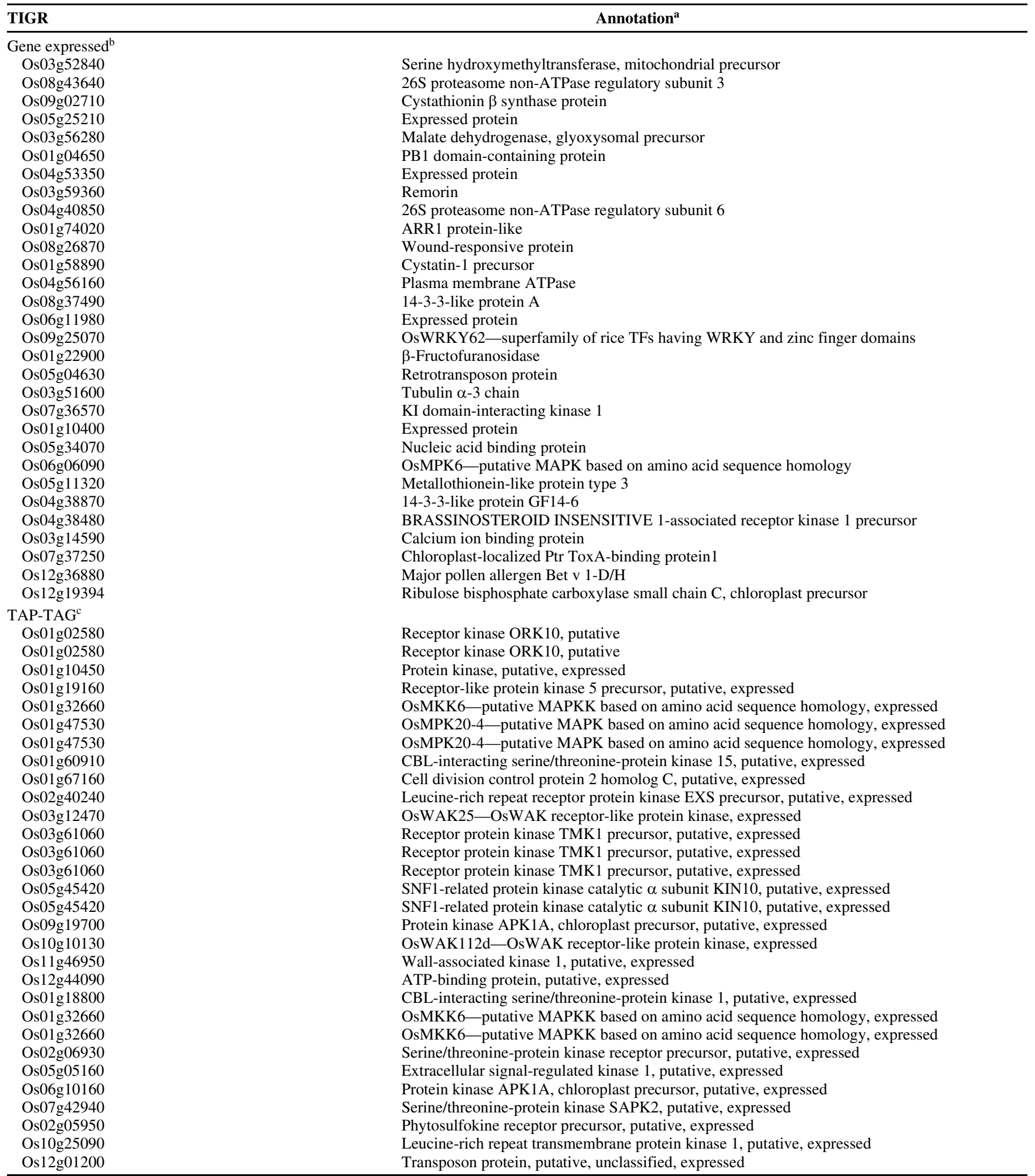

${ }^{\mathrm{a}}$ MAPK $=$ mitogen-activated protein kinase; $\mathrm{MAPKK}=$ MAPK-kinase.

${ }^{\mathrm{b}}$ Gene differentially expressed upon $M$. grisea infection.

${ }^{c}$ Tandem affinity purification tag (TAP-TAG) interactor. 
reviewed here. Overexpression of metallothionein OsMT2b has been shown to affect disease resistance (Wong et al. 2004). However, the OsMT2b gene (Os05g02070; Supplementary Table 2) was not the most common copy of this gene family in our database. The $P B Z 1$ gene, which belongs to the $P R 10$ family (Jwa et al. 2006) was also found to be differentially expressed under most conditions tested. This gene belongs to a large gene family in rice, members of which are often found in genomic clusters (Fig. 1 and discussed below). In Medicago truncatula, recent evidence suggests that silencing of some members of the PRIO gene family reduces susceptibility to a root-colonizing oomycete (Colditz et al. 2007). However, there is no direct evidence for the role of this gene in disease resistance in rice. The second class of genes (e.g., late embryogenesis proteins [LEA], peptidase, chaperonin, and Rubisco) likely represents functions indirectly affected by general cellular stress. Expression of LEA is usually linked to the acquisition of desiccation tolerance in seed, and many LEA proteins are induced by cold, osmotic stress or exogenous abscisic acid (Wise and Tunnacliffe 2004). The observation that one LEA is commonly found in our database supports cross-talk between biotic and abiotic stresses - a phenomenon also documented in rice (Xiong and Yang 2003). The roles of peptidase M16, chaperonin, and Rubisco in this list of genes are more enigmatic, although protein degradation (Vergne et al. 2007), protein folding (Arthur et al. 2007), and photosynthesis (Vergne et al. 2007) are all likely to be involved in disease resistance.

\section{Interactions between the kinome} and the rice defense arsenal.

Protein kinases have recently been used in TAP-TAG and yeast two-hybrid experiments to build a kinome interaction network (Dardick et al. 2007 and data downloaded from the Rice Kinase Database). The corresponding genes, which are included in ARCHIPELAGO, represent 95 original kinases used for TAP-TAG and yeast two-hybrid baits as well as the 291 identified targets (preys). A significant number of these targets (30 proteins) (Table 3) happened to be differentially regulated in interactions with Magnaporthe oryzae, corre- sponding to 11 of the 95 original kinases. Thus, a large portion (at least $10 \%$ ) of the genes that associate with kinases are defense-related genes. Interestingly, three proteins found to be ubiquitous markers (Table 2) also interacted with kinases: two metallothioneins (Os01g10400 and Os05g11320) and PBZ1 (Os12g36880).

Five of the kinases used as baits (Os01g47530, Os02g40240, Os10g10130, Os02g06930, and Os05g05160) that interact with defense-related genes were also described as differentially regulated upon infection. Like most kinases in Table 3, these genes belong to the RD kinases, a class of kinase not originally associated with disease resistance (Dardick et al. 2007). Five other kinases used as baits (Os01g02580, Os01g32660, Os01g47530, Os03g61060, and Os0545420) were found associated with two or three defenserelated genes, suggesting that large protein complexes could be transcriptionally regulated upon infection.

\section{Archipelago-like structure of the rice defense arsenal.}

In the course of building the ARCHIPELAGO resource, we often observed small regions of the genome where several paralogous copies of defense-related genes were concentrated in groups or clusters. Although this is well established for RGA (Monosi et al. 2004), this was quite unexpected for defense-related genes. Thus, we extensively scanned the rice genome using the dedicated software SCANBLOCK (J.-B. Morel and C. Perin, unpublished data) and identified the regions where such clusters occurred. The biological processes of the corresponding genes as well as a random control pool of genes were established using automated annotation tools (Ouyang et al. 2007; Yuan et al. 2005; data not shown) and are shown Figure 2. As expected, RGA are found organized in clusters (100 to 140 clusters detected). Some families, such as UDP-gulcosyl transferases (Fig. 2) and cytochrome P450 (included in secondary metabolism), were previously observed by Wisser and associates (2005). More surprisingly, all the biological processes that were organized in statistically significant clusters in this analysis can be attributed to defense-related genes or cell-wall modification enzymes. For example, Dirigent

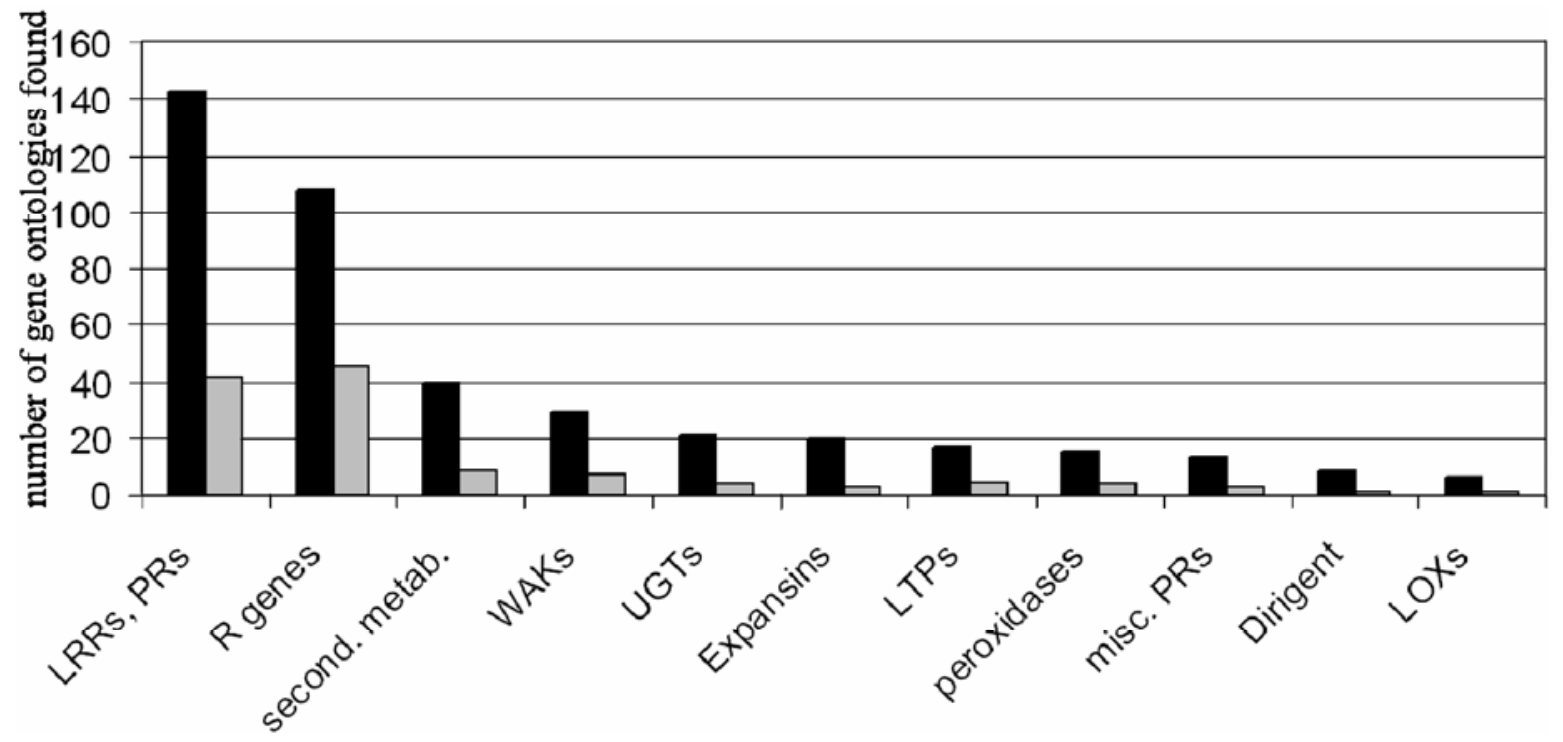

Fig. 2. Clusters of paralogs represent genes with functions related to disease resistance. Biological processes of the most statistically significant $(P<0.05$, Bonferroni correction) clusters of paralogs in the rice genome are shown. A gene ontology (biological process) was attributed to each of the 1,848 clusters detected in the genome (black bars) and to a random pool of 1,500 genes not found in clusters (gray bars). Classes of functions were introduced for simplicity (data not shown) and $\chi^{2}$ tests performed to compare clusters and random genes. A Bonferroni correction was included to take into account the number of tests. Only those classes for which the difference is significant are shown. LRR = leucine-rich repeat, WAK = wall-associated kinase, UGT = UDP-gulcosyl transferase, and LOX = lipoxygenase. 
proteins (Davin and Lewis 2005), expansins (Li et al. 2003), and wall-associated kinases (Kohorn 2001) are proteins involved in cell-wall modification. Thus, genes organized in clusters tend to be defense-related genes and genes participating in cell-wall integrity.

Reciprocally, using the ARCHIPELAGO resource, we tested whether defense-related genes were preferentially organized in clusters. We found that $15 \%$ of the 2,562 defense-related genes were found in clusters, compared with $8.6 \%$ of a random pool of genes (Supplementary Fig. 4). Thus, the kind of clusters found (e.g., for PBZ1) (Fig. 1) are common to a large portion of the genes annotated as involved in defense. Therefore, the rice defense arsenal, like the $R$ gene battery (Monosi et al. 2004), is organized in clusters of repeated copies of defenserelated genes.

The observation that only individual members of the $P B Z 1$ cluster on chromosome 12 seemed to be differentially expressed (Fig. 1) prompted further testing to determine whether there was a differential use of each copy of a given cluster. Using quantitative reverse-transcriptase polymerase chain reaction, we measured gene expression of individual members of three clusters upon M. oryzae infection (Fig. 3; Supplementary Table 4). These experiments showed that there was coexpression of the paralogous copies in some cases (Fig. 3A) but no apparent coexpression in others (Fig. 3B). Thus, more extensive genomewide transcription analysis is required to establish the rules for the expression of such gene clusters.

Finally, we examined defense-related gene density across rice chromosomes (Fig. 4). The defense-related gene density varied from 4.4 on chromosome 11 to 10.5 genes $/ 500 \mathrm{~kb}$ on chromosome 3. Thus, some chromosomes appear to be richer than others in the presence of defense-related genes. Surprisingly, chromosomes 11 and 12 are among the poorest in defenserelated genes whereas they are among the richest for RGA (The Rice Chromosomes 11 and 12 Sequencing Consortia 2005).

It also became apparent from this analysis that some regions of the genome accumulate large numbers of defense-related genes from different functional categories. For example, a hotspot of defense-related genes at the telomeric position of chromosome 12 contains 10 defense-related genes within $350 \mathrm{~kb}$ (Supplementary Fig. 5): one peroxidase, a cluster of five LTP (two of which are differentially expressed), and a cluster of four WRKY (three of which are differentially expressed). Thus, given this heterogeneity at the megabase level and the microstructure observed in clusters, the rice defense arsenal displays an archipelago-like structure.
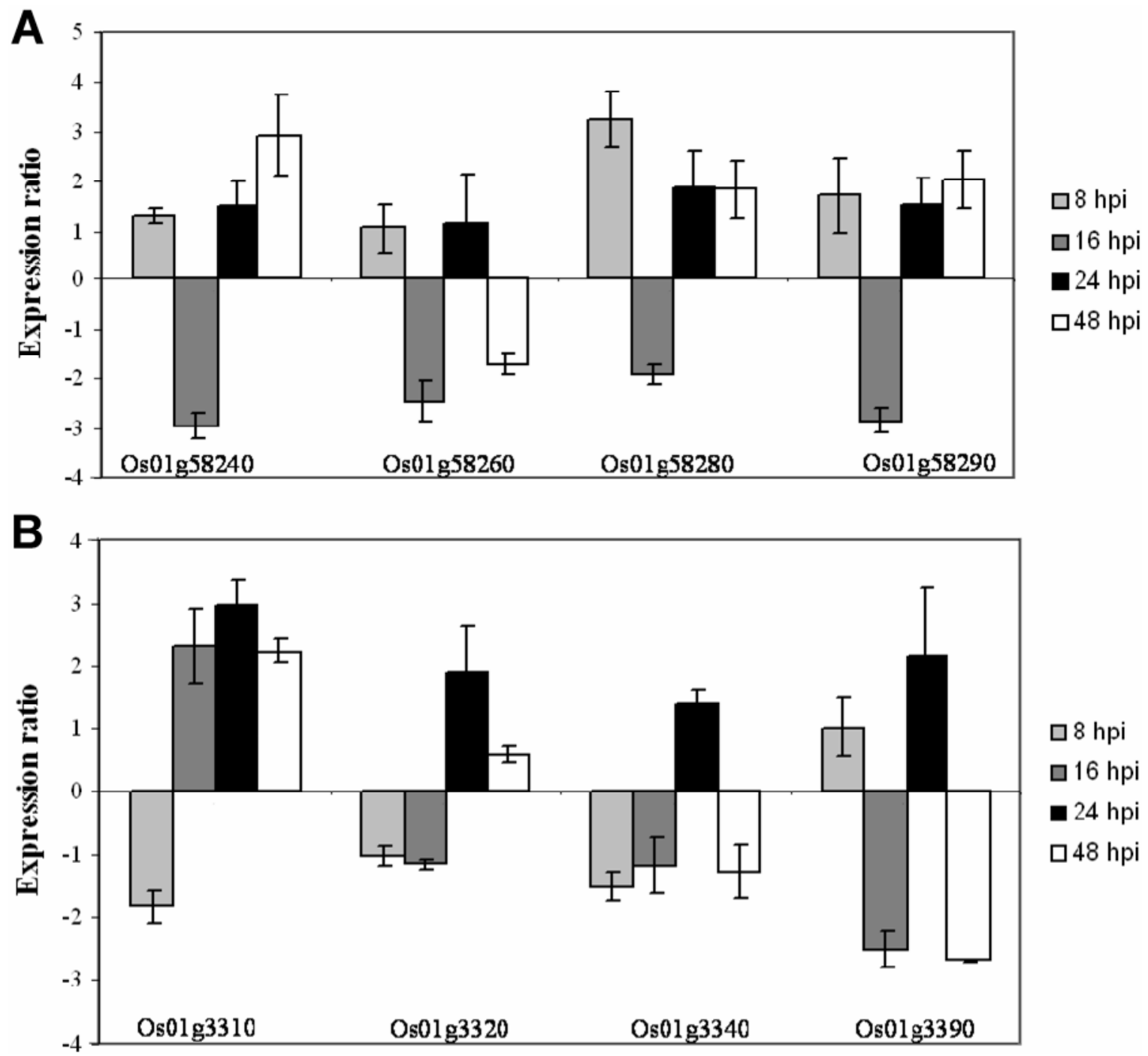

Fig. 3. Gene induction for two clusters of defense genes upon infection by Magnaporthe oryzae. Rice Nipponbare plants were infected with the avirulent isolate CL3.6.7. A, Four out of five members of a Subtilase cluster show coregulation; B, four out of seven members of a Bowman birk cluster are not coregulated. Mean ratios (infected versus noninfected) from three independent experiments are shown. Gene expression was measured by quantitative reverse-transcriptase polymerase chain reaction according to Vergne and associates (2007). hpi = hours postinoculation. 
Blast metaQTL colocalize with $I D R$ genes and $P R$ genes.

Ballini and associates (2008) detected no significant association between defense-related genes and QTL with disease resistance to blast. However, this could be due to the fact that defense-related genes are defined by their expression pattern, thus including genes that are indirectly differentially expressed upon infection. Therefore, these genes are not expected to directly participate to disease resistance. In their pioneering work, Wisser and associates (2005) did not detect statistical colocalization between disease resistance QTL and some candidate defense-related gene families known as putative regulators (WRKY, MYB, ERF, and bZIP). However, they observed that these families (except ERF) were more abundant in disease resistance QTL. Using the orthology database GreenPhylDB (Conte et al. 2008), we gathered a list of $377 P R$ genes from rice (Supplementary Table 5). We then asked for possible colocalizations between these $P R$ genes and blast metaQTL. We found significant associations between partial resistance metaQTL (Ballini et al. 2008) and PR1, chitinases (PR3, PR4, PR8, and PR11), PR6 (protease inhibitors), and PR13 (thionins). We also observed a significant colocalization of metaQTL and $I D R$ genes $(P<0.05)$, despite the limited number of identified $I D R$ or putative $I D R$ genes in rice (35 in this study). Thus, IDR genes and $P R$ genes seem to explain QTL better than defense-related genes.

Although there is no global colocalization of defense-related genes and metaQTL, it remains possible that defense-related genes are responsible for some QTL in some cases. We identified four QTL smaller than $500 \mathrm{~kb}$ in which defense-related gene density is high (Table 4) and where there is no RGA. Interestingly, one of these QTL (q6G12) (Ballini et al. 2008) contains two endochitinases. One of the latter is one of a small number of genes under the control of CeBIP receptor for chitin (Kaku et al. 2006).

\section{Concluding remarks.}

The ARCHIPELAGO resource, combined with QTL data (Ballini et al. 2008), provides an important source of informa- tion on genomic regions and markers that can be used for marker-assisted selection. For example, the genomic localization of disease regulators showed that, in some cases, several regulators (e.g., OsRacB, EDS5, and $O s B I-1$ on chromosome 2) are concentrated in small chromosomal regions (Fig. 4). This may have important implications for marker-assisted selection.

This resource should be further expanded, particularly to include pathogens other than Magnaporthe spp., and future work should focus on such pathogens to establish more accurately possible overlaps between different plant-pathogen interactions. We are currently developing a user-friendly webbased tool (G. Droc, unpublished) to allow the rapid and easy integration of new datasets into the ARCHIPELAGO resource by the rice community.

The question of possible colocalization of defense-related genes and QTL remains unanswered. Whereas Wisser and associates (2005) suggested possible colocalization, exhaustive analysis by Ballini and associates (2008) using the ARCHIPELAGO data set indicates that, so far, there is no statistically significant link between defense-related genes and QTL. This apparent discrepancy can be explained by a combination of several factors. First, QTL studied by Wisser and associates (2005) included QTL against several diseases (mostly rice blast and bacterial blight), under the assumption that there should be broad-spectrum resistance loci. In their accompanying article, Ballini and associates (2008) show that, even in the case of one disease (rice blast), very few broad-spectrum QTL are described in the literature. Thus, it is unlikely that the hypothesis made by Wisser and colleagues was fulfilled. Second, we showed that there is limited overlap between defenserelated genes induced by rice blast and bacterial blight. Thus, the mechanisms underlying resistance to these diseases may in fact be different, as also suggested by Li and associates (2006). However, testing $P R$ genes separately for colocalization with blast metaQTL indicates that some PR families are more often found in blast metaQTL than elsewhere in the genome. Thus, $P R$ genes represent potential candidates for QTL. The cloning of more disease QTL is now required to demonstrate globally

Table 4. Small meta-quantitative trait loci (QTL) rich in defense genes and devoid of resistance gene analogues

\begin{tabular}{|c|c|c|c|c|c|}
\hline \multirow[b]{2}{*}{ MetaQTL name ${ }^{a}$} & \multirow[b]{2}{*}{ Chr. ${ }^{b}$} & \multirow[b]{2}{*}{$\mathrm{CI}(\mathbf{k b})^{\mathrm{c}}$} & \multirow[b]{2}{*}{ Gene $^{\text {d }}$} & \multicolumn{2}{|r|}{ Defense gene content } \\
\hline & & & & Tigr name & Putative function $^{\mathrm{e}}$ \\
\hline \multirow[t]{5}{*}{ q2G9 } & 2 & 340 & 35 & Os02g56700 & Dihydroflavonol-4-reductase \\
\hline & & & & Os02g56810 & Phloem-specific lectin \\
\hline & & & & Os02g56850 & Glutathione reductase, cytosolic \\
\hline & & & & Os02g57160 & $\mathrm{ABC}-1$ \\
\hline & & & & Os02g57260 & 3-Ketoacyl-CoA thiolase 2, peroxisomal precursor \\
\hline \multirow[t]{6}{*}{ q5G7 } & 5 & 430 & 73 & Os05g50560 & OsMPK20-2_putative MAPK based on amino acid sequence homology \\
\hline & & & & Os05g50610 & OsWRKY8v2-superfamily of rice TFs having WRKY and zinc finger domains \\
\hline & & & & Os05g50624 & Transposon protein, putative, unclassified \\
\hline & & & & Os05g50750 & ATP-binding protein \\
\hline & & & & Os05g50770 & C4-dicarboxylate transporter/malic acid transport protein \\
\hline & & & & Os05g50890 & Indole-3-acetic acid-amido synthetase GH3.5 \\
\hline \multirow[t]{7}{*}{ q3G9 } & 3 & 310 & 42 & Os03g26970 & Proteasome subunit $\alpha$ type 2 \\
\hline & & & & Os03g27019 & Expressed protein \\
\hline & & & & Os03g27030 & Splicing factor, arginine/serine-rich 2 \\
\hline & & & & Os03g 27080 & Calmodulin-binding transcription activator 2 \\
\hline & & & & Os03g 27230 & Phospho-2-dehydro-3-deoxyheptonate aldolase 2, chloroplast precursor \\
\hline & & & & Os03g 27250 & Transferase, transferring glycosyl groups \\
\hline & & & & Os03g27310 & Histone $\mathrm{H} 3$ \\
\hline \multirow[t]{3}{*}{ q6G12 } & 6 & 90 & 11 & Os06g51029 & OsFtsH1-Oryza sativa FtsH protease, homologue of AtFtsH1/5 \\
\hline & & & & Os06g51050 & Basic endochitinase 1 precursor \\
\hline & & & & Os06g51060 & Basic endochitinase 1 precursor \\
\hline
\end{tabular}

\footnotetext{
a Information from Ballini and associates (2008).

${ }^{\mathrm{b}}$ Chromosome.

${ }^{\mathrm{c}}$ Confidence interval size.

${ }^{\mathrm{d}}$ Gene content. Pseudogenes have been eliminated.

${ }^{\mathrm{e}}$ MAPK $=$ mitogen-activated protein kinase.
} 

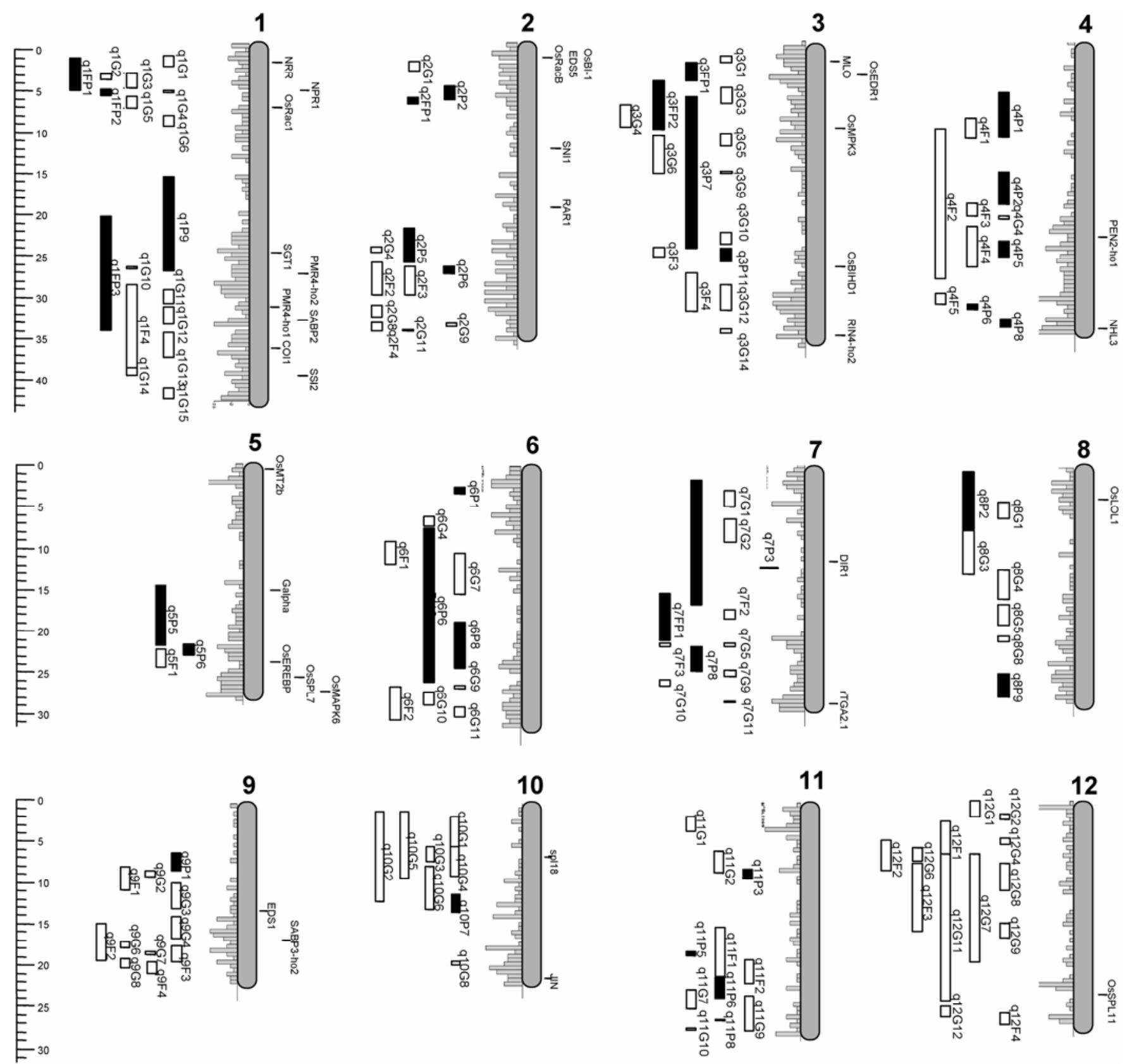

Fig. 4. Defense genes and meta-quantitative trait loci (QTL) against Magnaporthe oryzae. Chromosomes were drawn according to genome physical data (scale bar). Intracellular disease regulator (IDR) genes are indicated to the right of each chromosome. MetaQTL are indicated as bars to the left of the chromosomes. Black bars represent "partial resistance metaQTL" and white bars represent other metaQTL (Ballini et al. 2008). The histograms attached to the chromosomes represent the defense gene density, as calculated in a sliding window of $500 \mathrm{~kb}$. In QTL names, "F" represent field resistance metaQTL, "G" represent greenhouse resistance metaQTL, and "P" represent partial resistance metaQTL.

whether defense-related genes, $I D R$ genes, or $P R$ genes are behind QTL.

With the availability of the rice genome and metaQTL on the one hand and of insertion libraries and deletion mutants on the other, cloning metaQTL in rice is now feasible. Candidate gene approaches using reverse genetics strategies (Droc et al. 2006) can now be applied to small metaQTL to complete our understanding of quantitative resistance in rice.

The observation that the rice defense arsenal is massively organized in clusters adds a new layer of complexity to the disease resistance pathway. That $R$ genes are clustered in the genomes of plants is well known. This likely favors unequal crossing-over and subsequent production of new alleles to face constantly changing pathogen populations (Michelmore and Meyers 1998). The most evolutionarily successful tandem du- plication events are most likely to target genes at the end of biochemical pathways or genes representing flexible steps in a pathway, such as $P R$ genes, where fluctuation in copy number is unlikely to affect downstream genes. It may not be surprising that clustered genes are enriched for duplication of biotic response genes, because these may provide a rich source of environmental responses, often without substantial damage to critical steps in genetic networks.

\section{ACKNOWLEDGMENTS}

E. Vergne was funded by a joint grant from Institut National de la Recherche Agronomique (INRA) and the Languedoc-Rousillon region. E. Ballini was supported by grants of the French Ministry of Research and CIRAD. Part of this work was supported by the French programme Génoplante (projects B8). We thank C. Périn for critical reading of the manuscript. 


\section{LITERATURE CITED}

An, G., Jeong, D. H., Jung, K. H., and Lee, S. 2005. Reverse genetic approaches for functional genomics of rice. Plant Mol. Biol. 59:111123.

Arthur, J. C., Lich, J. D., Aziz, R. K., Kotb, M., and Ting, J. P. 2007. Heat Shock Protein 90 Associates with Monarch-1 and Regulates Its Ability to Promote Degradation of NF-\{kappa\}B-Inducing Kinase. J. Immunol. 179:6291-6296.

Ballini, E., Morel, J.-B., Droc, G., Price, A., Courtois, B., Notteghem, J.L., Tharreau, D. 2008. A genome-wide meta-analysis of rice blast resistance genes and quantitative trait loci provides new insights into partial and complete resistance. Mol. Plant-Microbe Interact. 21:859-868.

Bent, A. F., and Mackey, D. 2007. Elicitors, effectors, and $R$ genes: The new paradigm and a lifetime supply of questions. Annu. Rev. Phytopathol. 45:399-436.

Button, D. K., Gartland, K. M., Ball, L. D., Natanson, L., Gartland, J. S., and Lyon, G. D. 2006. DRASTIC-INSIGHTS: Querying information in a plant gene expression database. Nucleic Acids Res. 3:D712D716.

Chittoor, J. M., Leach, J. E., and White, F. F. 1997. Differential induction of a peroxidase gene family during infection of rice by Xanthomonas oryzae pv. oryzae. Mol. Plant-Microbe Interact. 10:861-871.

Colditz, F., Niehaus, K., and Krajinski, F. 2007. Silencing of PR-10-like proteins in Medicago truncatula results in an antagonistic induction of other PR proteins and in an increased tolerance upon infection with the oomycete Aphanomyces euteiches. Planta 226:57-71.

Conte, M., Gaillard, S., Lanau, N., Rouard, M., and Périn C. 2008. GreenPhylDB: A database for plant comparative genomics. Nucleic Acids Res. 36:D991-998.

Dangl, J. L., and Jones, J. D. 2001. Plant pathogens and integrated defence responses to infection. Nature 411:826-833.

Dardick, C., Chen, J., Richter, T., Ouyang, S., and Ronald, P. 2007. The rice kinase database. A phylogenomic database for the rice kinome. Plant Physiol. 143:579-586.

Davin, L. B., and Lewis, N. G. 2005. Lignin primary structures and dirigent sites. Curr. Opin. Biotechnol. 16:407-415.

Dean, R. A., Talbot, N. J., Ebbole, D. J., Farman, M. L., Mitchell, T. K., Orbach, M. J., Thon, M., Kulkarni, R., Xu, J. R., Pan, H., Read, N. D., Lee, Y. H., Carbone, I., Brown, D., Oh, Y. Y., Donofrio, N., Jeong, J. S., Soanes, D. M., Djonovic, S., Kolomiets, E., Rehmeyer, C., Li, W., Harding, M., Kim, S., Lebrun, M. H., Bohnert, H., Coughlan, S., Butler, J., Calvo, S., Ma, L. J., Nicol, R., Purcell, S., Nusbaum, C., Galagan, J. E., and Birren, B. W. 2005. The genome sequence of the rice blast fungus Magnaporthe grisea. Nature 434:980-986.

Diener, A. C., and Ausubel, F. M. 2005. RESISTANCE TO FUSARIUM OXYSPORUM 1, a dominant Arabidopsis disease-resistance gene, is not race specific. Genetics 171:305-321.

Droc, G., Ruiz, M., Larmande, P., Pereira, A., Piffanelli, P., Morel, J. B., Dievart, A., Courtois, B., Guiderdoni, E., and Perin, C. 2006. OryGenesDB: A database for rice reverse genetics. Nucleic Acids Res. 34:D736-D740.

Eulgem, T. 2005. Regulation of the Arabidopsis defense transcriptome. Trends Plant Sci. 10:71-78.

Goff, S. A., Ricke, D., Lan, T. H., Presting, G., Wang, R., Dunn, M., Glazebrook, J., Sessions, A., Oeller, P., Varma, H., Hadley, D., Hutchison, D., Martin, C., Katagiri, F., Lange, B. M., Moughamer, T., Xia, Y., Budworth, P., Zhong, J., Miguel, T., Paszkowski, U., Zhang, S., Colbert, M., Sun, W. L., Chen, L., Cooper, B., Park, S., Wood, T. C., Mao, L., Quail, P., Wing, R., Dean, R., Yu, Y., Zharkikh, A., Shen, R., Sahasrabudhe, S., Thomas, A., Cannings, R., Gutin, A., Pruss, D., Reid, J., Tavtigian, S., Mitchell, J., Eldredge, G., Scholl, T., Miller, R. M., Bhatnagar, S., Adey, N., Rubano, T., Tusneem, N., Robinson, R., Feldhaus, J., Macalma, T., Oliphant, A., and Briggs, S. 2002. A draft sequence of the rice genome (Oryza sativa L. ssp. japonica). Science 296(5565):92-100.

Greenberg, J. T., and Yao, N. 2004. The role and regulation of programmed cell death in plant-pathogen interactions. Cell Microbiol. 6:201-211.

Hückelhoven, R. 2007. Cell wall-associated mechanisms of disease resistance and susceptibility. Annu. Rev. Phytopathol. 45:101-127.

Jones, J. D., and Dangl, J. L. 2006. The plant immune system. Nature 444:323-329.

Juge, N. 2006. Plant protein inhibitors of cell wall degrading enzymes. Trends Plant Sci. 11:359-367.

Jwa, N. S., Agrawal, G. K., Tamogami, S., Yonekura, M., Han, O., Iwahashi, H., and Rakwal, R. 2006. Role of defense/stress-related marker genes, proteins and secondary metabolites in defining rice selfdefense mechanisms. Plant Physiol. Biochem. 44:261-273.

Kaku, H., Nishizawa, Y., Ishii-Minami, N., Akimoto-Tomiyama, C.,
Dohmae, N., Takio, K., Minami, E., and Shibuya, N. 2006. Plant cells recognize chitin fragments for defense signaling through a plasma membrane receptor. Proc. Natl. Acad. Sci. U.S.A. 103(29):11086-11091.

Khush, G. S. 2005. What it will take to feed 5.0 billion rice consumers in 2030. Plant Mol Biol. 59(1):1-6.

Kohorn, B. D. 2001. WAKs; cell wall associated kinases. Curr. Opin. Cell Biol. 13:529-533.

Lee, B. M., Park, Y. J., Park, D. S., Kang, H. W., Kim, J. G., Song, E. S., Park, I. C., Yoon, U. H., Hahn, J. H., Koo, B. S., Lee, G. B., Kim, H., Park, H. S., Yoon, K. O., Kim, J. H., Jung, C. H., Koh, N. H., Seo, J. S., and Go, S. J. 2005. The genome sequence of Xanthomonas oryzae pathovar oryzae KACC10331, the bacterial blight pathogen of rice. Nucleic Acids Res. 33:577-586.

Li, Q., Chen, F., Sun, L., Zhang, Z., Yang, Y., and He Z. 2006. Expression profiling of rice genes in early defense responses to blast and bacterial blight pathogens using cDNA microarray. Physiol. Mol. Plant Pathol. 68:51-60.

Li, Y., Jones, L., and McQueen-Mason, S. 2003. Expansins and cell growth. Curr. Opin. Plant Biol. 6:603-610.

Liu, B., Zhang, S., Zhu, X., Yang, Q., Wu, S., Mei, M., Mauleon, R., Leach, J., Mew, T., and Leung, H. 2004. Candidate defense genes as predictors of quantitative blast resistance in rice. Mol. Plant-Microbe Interact. 10:1146-1152.

Michelmore, R. W., and Meyers, B. C. 1998. Clusters of resistance genes in plants evolve by divergent selection and a birth-and-death process. Genome Res. 11:1113-1130.

Mishra, N. S., Tuteja, R., and Tuteja, N. 2006. Signaling through MAP kinase networks in plants. Arch. Biochem. Biophys. 452:55-68.

Miyao, A., Iwasaki, Y., Kitano, H., Itoh, J. I., Maekawa, M., Murata, K., Yatou, O., Nagato, Y., and Hirochika, H. 2007. A large-scale collection of phenotypic data describing an insertional mutant population to facilitate functional analysis of rice genes. Plant Mol. Biol. 63:625-635.

Monosi, B., Wisser, R. J., Pennill, L., and Hulbert, S. H. 2004. Fullgenome analysis of resistance gene homologues in rice. Theor. Appl. Genet. 109(7):1434-1447.

Ouyang, S., Zhu, W., Hamilton, J., Lin, H., Campbell, M., Childs, K., Thibaud-Nissen, F., Malek, R. L., Lee, Y., Zheng, L., Orvis, J., Haas, B., Wortman, J., and Buell, C. R. 2007. The TIGR Rice Genome Annotation Resource: Improvements and new features. Nucleic Acid Res. 35:D846-851.

Peters, R. J. 2006. Uncovering the complex metabolic network underlying diterpenoid phytoalexin biosynthesis in rice and other cereal crop plants. Phytochemistry 67:2307-2317.

Ramalingam, J., Vera Cruz, C. M., Kukreja, K., Chittoor, J. M., Wu, J. L., Lee, S. W., Baraoidan, M., George, M. L., Cohen, M. B., Hulbert, S. H., Leach, J. E., and Leung, H. 2003. Candidate defense genes from rice, barley, and maize and their association with qualitative and quantitative resistance in rice. Mol. Plant-Microbe Interact. 16:14-24.

Rice Chromosomes 11 and 12 Sequencing Consortia. 1005. The sequence of rice chromosomes 11 and 12, rich in disease resistance genes and recent gene duplications. BMC Biol. 3:20.

Rizzon, C., Ponger, L., and Gaut, B. S. 2006. Striking similarities in the genomic distribution of tandemly arrayed genes in Arabidopsis and rice. PLoS Comput. Biol. 2(9):e115.

Sallaud, C., Gay, C., Larmande, P., Bès, M., Piffanelli, P., Piégu, B., Droc, G., Regad, F., Bourgeois, E., Meynard, D., Périn, C., Sabau, X., Ghesquière, A., Glaszmann, J. C., Delseny, M., and Guiderdoni, E. 2004. High throughput T-DNA insertion mutagenesis in rice: A first step towards in silico reverse genetics. Plant J. 39:450-64.

Shimamoto, K., and Kyozuka, J. 2002. Rice as a model for comparative genomics of plants. Annu. Rev. Plant Biol. 53:399-419.

Skamnioti, P., and Gurr, S. J. 2007. Magnaporthe grisea cutinase2 mediates appressorium differentiation and host penetration and is required for full virulence. Plant Cell 19:2674-2689.

Toki, S., Hara, N., Ono, K., Onodera, H., Tagiri, A., Oka, S., and Tanaka, H. 2006. Early infection of scutellum tissue with Agrobacterium allows high-speed transformation of rice. Plant J. 47(6):969-976.

Valent, B. 2004. Plant disease: Underground life for rice foe. Nature 431(7008):516-517.

Vergne, E., Ballini, E., Marques, S., Sidi Mammar, B., Droc, G., Gaillard, S., Bourot, S., DeRose, R., Tharreau, D., Nottéghem, J. L., Lebrun, M. H., and Morel J. B. 2007. Early and specific gene expression triggered by rice resistance gene Pi33 in response to infection by ACE1 avirulent blast fungus. New Phytol. 174(1):159-171.

Walling, L. L. 2006.Recycling or regulation? The role of amino-terminal modifying enzymes. Curr. Opin. Plant Biol. 9:227-233.

Wise, M. J, and Tunnacliffe, A. 2004. POPP the question: What do LEA proteins do? Trends Plant Sci. 9:13-17.

Wisser, R. J., Sun, Q., Hulbert, S. H., Kresovich, S., and Nelson, R. J. 2005. Identification and characterization of regions of the rice genome 
associated with broad-spectrum, quantitative disease resistance. Genetics 169:2277-2293.

Wong, H. L., Sakamoto, T., Kawasaki, T., Umemura, K., and Shimamoto, K. 2004. Down-regulation of metallothionein, a reactive oxygen scavenger, by the small GTPase OsRac1 in rice. Plant Physiol. 135:14471456.

Wu, J. L., Wu, C., Lei, C., Baraoidan, M., Bordeos, A., Madamba, M. R., Ramos-Pamplona, M., Mauleon, R., Portugal, A., Ulat, V. J., Bruskiewich, R., Wang, G., Leach, J., Khush, G., and Leung, H. 2005. Chemical- and irradiation-induced mutants of indica rice IR64 for forward and reverse genetics. Plant Mol. Biol. 59:85-97.

Xiong, L., and Yang, Y. 2003. Disease resistance and abiotic stress tolerance in rice are inversely modulated by an abscisic acid-inducible mitogen-activated protein kinase. Plant Cell 15:745-759.

Yassi, M. N., Ritzenthaler, C., Brugidou, C., Fauquet, C., and Beachy, R. N. 1994. Nucleotide sequence and genome characterization of rice yellow mottle virus RNA. J. Gen. Virol. 75:249-257.

Yuan, Q., Ouyang, S., Wang, A., Zhu, W., Maiti, R., Lin, H., Hamilton, J., Haas, B., Sultana, R., Cheung, F., Wortman, J., and Buell, C. R. 2005. The institute for genomic research osa1 rice genome annotation database. Plant Physiol. 138:18-26.

Yu, J., Hu, S., Wang, J., Wong, G. K., Li, S., Liu, B., Deng, Y., Dai, L., Zhou, Y., Zhang, X., Cao, M., Liu, J., Sun, J., Tang, J., Chen, Y., Huang, X., Lin, W., Ye, C., Tong, W., Cong, L., Geng, J., Han, Y., Li, L., Li, W.,
Hu, G., Huang, X., Li, W., Li, J., Liu, Z., Li, L., Liu, J., Qi, Q., Liu, J. Li, L., Li, T., Wang, X., Lu, H., Wu, T., Zhu, M., Ni, P., Han, H., Dong, W., Ren, X., Feng, X., Cui, P., Li, X., Wang, H., Xu, X., Zhai, W., Xu, Z., Zhang, J., He, S., Zhang, J., Xu, J., Zhang, K., Zheng, X., Dong, J., Zeng, W., Tao, L., Ye, J., Tan, J., Ren, X., Chen, X., He, J., Liu, D., Tian, W., Tian, C., Xia, H., Bao, Q., Li, G., Gao, H., Cao, T., Wang, J., Zhao, W., Li, P., Chen, W., Wang, X., Zhang, Y., Hu, J., Wang, J., Liu, S., Yang, J., Zhang, G., Xiong, Y., Li, Z., Mao, L., Zhou, C., Zhu, Z., Chen, R., Hao, B., Zheng, W., Chen, S., Guo, W., Li, G., Liu, S., Tao, M., Wang, J., Zhu, L., Yuan, L., and Yang, H. 2002. A draft sequence of the rice genome (Oryza sativa L. ssp. indica). Science 296(5565):79-92

Zhang, J., Li, C., Wu, C., Xiong, L., Chen, G., Zhang, Q., and Wang, S. 2006. RMD: A rice mutant database for functional analysis of the rice genome. Nucleic Acids Res. 34:D745-D748.

Zimmermann, P., Hirsch-Hoffmann, M., Hennig, L., and Gruissem, W. 2004. GENEVESTIGATOR. Arabidopsis microarray database and analysis toolbox. Plant Physiol. 136:2621-2632.

\section{AUTHOR-RECOMMENDED INTERNET RESOURCES}

University of California-Davis Rice Kinase database: rkd.ucdavis.edu OryGenesDB database: orygenesdb.cirad.fr/

GreenPhylDB database: greenphyl.cines.fr/ 